\title{
Cross-linked polyethylenimine-tripolyphosphate nanoparticles for gene delivery
}

This article was published in the following Dove Press journal:

International Journal of Nanomedicine

16 October 2014

Number of times this article has been viewed

\section{Xianzhang Huang' \\ Sujing Shen ${ }^{2}$ \\ Zhanfeng Zhang' \\ Junhua Zhuang'}

'Department of Laboratory Science, Second Affiliated Hospital

of Guangzhou University of Chinese

Medicine, ${ }^{2}$ Department of Laboratory

Science, Guangdong Second Provincial

Traditional Chinese Medicine Hospital,

Guangzhou, People's Republic

of China
Correspondence: Xianzhang Huang Department of Laboratory Science, Second Affiliated Hospital of Guangzhou University of Chinese Medicine, I I I Dade Road, Guangzhou, Guangdong 510120 , People's Republic of China Tel/fax +86208I88 7233 ext 32908 Email huangxz020@I63.com
Abstract: The high transfection efficiency of polyethylenimine (PEI) makes it an attractive potential nonviral genetic vector for gene delivery and therapy. However, the highly positive charge of PEI leads to cytotoxicity and limits its application. To reduce the cytotoxicity of PEI, we prepared anion-enriched nanoparticles that combined PEI with tripolyphosphate (TPP). We then characterized the PEI-TPP nanoparticles in terms of size, zeta potential, and Fouriertransform infrared (FTIR) spectra, and assessed their transfection efficiency, cytotoxicity, and ability to resist deoxyribonuclease (DNase) I digestion. The cellular uptake of PEI-TPP with phosphorylated internal ribosome entry site-enhanced green fluorescent protein $\mathrm{C} 1$ or FAM (fluorouracil, Adriamycin [doxorubicin] and mitomycin)-labeled small interfering ribonucleic acids (siRNAs) was monitored by fluorescence microscopy and confocal laser microscopy. The efficiency of transfected delivery of plasmid deoxyribonucleic acid (DNA) and siRNA in vitro was 1.11 - to 4.20 -fold higher with the PEI-TPP particles ( $7.6 \%$ cross-linked) than with the PEI at all N:P ratios (nitrogen in PEI to phosphorus in DNA) tested. The cell viability of different cell lines was more than $90 \%$ at the chosen N:P ratios of PEI-TPP/DNA complexes. Moreover, PEI-TPP nanoparticles resisted digestion by DNase I for more than 2 hours. The time-dependent absorption experiment showed that $7.6 \%$ of cross-linked PEI-TPP particles were internalized by 293 T cells within 1 hour. In summary, PEI-TPP nanoparticles effectively transfected cells while conferring little or no toxicity, and thus have potential application in gene delivery.

Keywords: polyethylenimine (PEI), tripolyphosphate (TPP), nanoparticles (NPs), transfection

\section{Introduction}

Viral and nonviral systems have been widely used for gene delivery. ${ }^{1-4}$ While viral delivery systems can protect deoxyribonucleic acid (DNA) against degradation from intracellular enzymes, they may cause an uncertain immune response, leading to toxic effects. ${ }^{5,6}$ Therefore, it is important to develop nonviral delivery systems with improved safety.

Nonviral delivery vectors may consist of cell-penetrating peptides, polymers, liposomes, or dendrimers (multibranched polymers). ${ }^{7-9}$ An example is the cationic polyethylenimine (PEI). In every macromolecule of PEI, a third of the amino nitrogen can be protonated and catalyzed into a polymer with high-density cationic potential and a highly branched network. Owing to this property, PEI can concentrate DNA and penetrate cells. PEI penetrates the endosome by means of osmotic imbalance, known as the proton-sponge effect. Moreover, PEI is a stable buffer under different $\mathrm{pH}$ conditions. ${ }^{10}$

Several studies have shown that PEI-based nonviral vectors can be locally delivered to target tumors. ${ }^{11,12}$ However the application of these vectors in gene delivery and therapy is limited, due to their high cytotoxicity. To minimize the cationic charge on PEI and 
decrease its charge-related toxicity, such ligands as peptides, polysaccharides, polyethylene glycols, antibodies, imidazolyl, and acyl functional groups have been used. ${ }^{11-17}$

Anionic tripolyphosphate (TPP) molecules possess multipoint-attachment sites, through which PEI-TPP nanoparticles can be formed. Because of the polyanionic charge of TPP, many studies have chosen it to cross-link with chitosan to carry drugs or target genes. ${ }^{18,19}$ In the present study, we used an ionotropic gelation method ${ }^{20}$ to link PEI to TPP. We then characterized the main physical properties of the new nanoparticles with regard to size, zeta potential, and Fourier-transform infrared (FTIR) spectra. The ability to deliver DNA and small interfering ribonucleic acid (siRNA) and protect DNA from nucleases was investigated as well.

\section{Methods and materials}

\section{Reagents}

PEI (average molecular weight $25 \mathrm{kDa}), 3-(4,5$-dimethylthiazol-2-yl)-2,5-diphenyltetrazolium bromide (MTT), agarose, ethidium bromide, bromophenol blue, and 4',6-diamidino-2phenylindole (DAPI) dilactate were purchased from SigmaAldrich (St Louis, MO, USA). Sodium TPP was purchased from Guangzhou Chemical (Guangzhou, People's Republic of China). Dulbecco's Modified Eagle's Medium (DMEM) and fetal calf serum (FCS) were purchased from Thermo Fisher Scientific (Waltham, MA, USA).

Plasmid DNA (pDNA; phosphorylated internal ribosome entry site-enhanced green fluorescent protein [EGFP] C1) was preserved in our laboratory. Human papillomavirus (HPV) 16 E6 siRNA labeled 6-carboxyfluorescein (FAM [fluorouracil, Adriamycin \{doxorubicin\}], mitomycin): HPV E6 (sense, 5'-GAG GUA UAU GAC UUU GCU UTT-3'; antisense, 5'-AAG CAA AGU CAU AUA CCU CTT-3') was synthesized by GenePharma (Shanghai, People's Republic of China).

Reagent A (2.5\% ammonium molybdate in $3 \mathrm{M} \mathrm{HCl})$ and reagent $\mathrm{B}$ (sodium bisulfite [5.44 g], sodium sulfite [0.4 g], and 1,2,4-aminonaphthol sulfonic acid [0.2 g] dissolved in $200 \mathrm{~mL}$ water) were prepared in the lab. Ethylenediaminetetraacetic acid (EDTA) was purchased from Shanghai Chemical Reagent Factory (Shanghai, People's Republic of China). All other chemicals used were of the highest quality commercially available.

\section{Other materials}

Human embryonic kidney (HEK)-293T, hepatocellular carcinoma HepG2, breast cancer (Michigan Cancer Foundation [MCF]-7), and cervical cancer HeLa cells were purchased from the cell bank of the Chinese Academy of Sciences
(Beijing, People's Republic of China). Primary rabbit osteoarthritis synovial fibroblasts (rOASFs) were isolated from a rabbit osteoarthritis model.

\section{Preparation of PEI-TPP nanoparticles}

An aqueous solution of $50 \mathrm{~mL} 4 \%$ sodium tripolyphosphate was added dropwise to $40 \mathrm{~mL} \mathrm{HCl}(0.1 \mathrm{M})$ to be acidified, and the mixture was freeze-dried to produce tripolyphosphoric acid. Then, 1\% (5 mL) tripolyphosphoric acid aqueous solution was added dropwise to $1 \mathrm{~mL}$ PEI aqueous solution $(0.1 \%)$, with continuous stirring for 4 hours for $5 \%$ cross-linking. The final product was collected by dialysis against deionized water for 3 days and then vacuum-dried at $-50^{\circ} \mathrm{C}$ for 2 days to get powdered PEITPP nanoparticles. Concentrations of $10 \%, 15 \%$, or $20 \%$ cross-linking of PEI-TPP nanoparticles were prepared in the same manner.

The binding rate of tripolyphosphate in the PEI-TPP particles was evaluated by measuring the quantity of phosphate, in accordance with the literature. ${ }^{21}$ In brief, $1 \mu \mathrm{g}$ PEI-TPP nanoparticles was dissolved in $1 \mathrm{~mL} 60 \%$ perchloric acid for 2 hours. The final volume of the mixture was added to $10 \mathrm{~mL}$ water, when cooled to room temperature. Test tubes with $6 \mathrm{~mL}$ or $10 \mathrm{~mL}$ of nanoparticle solution were brought to a final volume of $16 \mathrm{~mL}$ with water. These were mixed with $2.0 \mathrm{~mL}$ of reagent $\mathrm{A}$ and reagent $\mathrm{B}$, incubated for 10 minutes, and then the absorbance was measured at $660 \mathrm{~nm} \cdot{ }^{21,22}$

\section{Size and zeta-potential measurement}

A laser particle-size analyzer and a zeta-potential analyzer (Zetasizer Nano ZS, Malvern Instruments, Malvern, UK) were used to measure the average diameter and zeta potential of the PEI-TPP nanoparticles, with an N:P ratio (ie, the nitrogen in PEI to the phosphorus in DNA) of $10.2 \%$. Briefly, $200 \mu \mathrm{g}$ of lyophilized nanoparticles were dissolved in $1 \mathrm{~mL}$ double-distilled water and sonicated. The size and zeta potential were measured with relevant analyzers. Data are reported as the average of three measurements.

\section{FTIR}

FTIR spectra were obtained using a $\mathrm{KBr}$ pellet in an FTIR spectrophotometer (Nicolet 6700; Thermo Fisher Scientific), using the $10.2 \%$ cross-linking rate of PEI-TPP as the candidate. Infrared spectroscopy-grade $\mathrm{KBr}$ was used as a scanning matrix. From 1 to $2 \mathrm{mg}$ of fine sample powder and 90-100 mg of $\mathrm{KBr}$ powder were mixed and dried completely, then transferred to a $13 \mathrm{~mm}$ die to make a nearly transparent and homogeneous 
pellet. ${ }^{18}$ All spectra were taken at $4 \mathrm{~cm}^{-1}$ resolution, averaged over 40 scans in the range $400-4,000 \mathrm{~cm}^{-1}$.

\section{Gel retardation assay}

PEI-TPP nanoparticles were mixed with $1 \mathrm{mg}$ pDNA at N:P ratios of 1:1, 5:1, 10:1, 15:1, 20:1, or 25:1 in 5\% dextrose, while PEI and pDNA were mixed at N:P ratios 5:1, 10:1, or 15:1. All the mixtures were incubated for 30 minutes at room temperature, electrophoresed in a $1 \%$ agarose gel, and after staining with ethidium bromide for 20 minutes visualized on an ultraviolet transilluminator.

\section{DNase digestion assay}

For the deoxyribonuclease (DNase) I protection assay, $2 \mu \mathrm{g}$ pDNA was complexed with $20 \mu \mathrm{L}$ of PEI-TPP (N:P ratio of 10:1) to get the DNA complex. Ten microliters of naked pDNA and DNA complex were added with one unit DNase I $(1 \mu \mathrm{L})$ or $1 \mu \mathrm{L}$ phosphate-buffered saline (PBS; as control). The mixture was incubated in a $37^{\circ} \mathrm{C}$ water bath for $15,30,60$, or 120 minutes. Then, $1 \mu \mathrm{L}$ of $100 \mathrm{mM}$ EDTA was added to stop the reaction. The samples were heated at $75^{\circ} \mathrm{C}$ for 10 minutes to inactivate DNase I. Finally, the complex was dissociated by incubation with $10 \mu \mathrm{L}$ heparin $(5 \mathrm{mg} / \mathrm{mL}$ ) for 2 hours at room temperature. All the samples were electrophoresed in $1 \%$ agarose, then stained with ethidium bromide for 20 minutes and photographed with an Alphalmager ${ }^{\circledR}$ EP image-acquisition system (ProteinSimple, Santa Clara, CA, USA).

\section{Uptake of FAM-labeled siRNA}

To investigate the intracellular uptake of PEI-TPP nanoparticles in vitro, HEK293T cells were plated in six-well microplates with filled circular glass slides and incubated overnight in DMEM replenished with $10 \%$ FCS to $~ 70 \%$ confluence. Then, the cells were cocultured with PEI-TPP (7.6\%) and PEI-TPP (7.6\%)/FAM-labeled HPV E6 siRNA mixture in DMEM for 15, 30, 60, 120, 180, or 240 minutes. The plates were gently washed with sterile PBS three times and cells were fixed in 4\% paraformaldehyde in PBS for 15 minutes at room temperature, then washed three times with PBS, stained with DAPI, and mounted on clean glass slides with fluorescence-free glycerol-based mounting medium. Finally, the slides were observed under a confocal microscope (FluoView ${ }^{\circledR}$ FV-1000; Olympus, Tokyo, Japan).

The cell lines HEK293T and HepG2 were purchased from the cell bank of the Chinese Academy of Sciences. rOASFs were isolated from a rabbit osteoarthritis model as reported previously. ${ }^{23}$ The cells were cultured in 10\% FCS DMEM.
The third to fifth generations were used in the experiments. HEK293T and HepG2 cells, or rOASFs, were plated in 24-well plates. After 20 hours, the medium was discarded, and cells were washed once with serum-free DMEM. Two microliters of FAM-labeled siRNA $(100 \mathrm{nM})$ and PEITPP at different N:P ratios (1:1, 5:1, 10:1, 15:1, 20:1, or 25:1) were mixed with $100 \mu \mathrm{L}$ PBS. The siRNA was dropped into the six given N:P ratios of PEI-TPP and incubated for 20 minutes. The resultant transfection media were all dropped into each well. Four hours later, the coculture medium was aspirated and $500 \mu \mathrm{L}$ fresh $10 \%$ FCS DMEM was replenished to each well, and then cells were incubated up to 36 hours. Cells treated with only PEI-TPP nanoparticles served as the controls. The transfection effect of FAM-labeled siRNA was assessed in an inverted fluorescence microscope after transfection for 36 hours, based on the number of cells with green fluorescence.

\section{In vitro transfection efficiency of PEI-TPP nanoparticles}

HEK293T, MCF-7, HeLa, and HepG2 cells and rOASFs were seeded in 24-well plates. After 20 hours, the medium was discarded, and cells were washed once with serum-free DMEM. Vector pEGFP-C1 $(1 \mu \mathrm{g})$ and PEI-TPP at different $\mathrm{N}: \mathrm{P}$ ratios $(1: 1,5: 1,10: 1,15: 1,20: 1$, or 25:1) or PEI (N:P 5:1, 10:1, or 15:1) were mixed with $100 \mu \mathrm{L}$ PBS. pEGFP-C1 was dropped into the given N:P ratios of PEI-TPP or PEI and incubated for 20 minutes. The resultant transfection medium was added to each well. After 4 hours, the transfection mixture was aspirated and $500 \mu \mathrm{L}$ fresh 10\% FCS DMEM was added to each well, and cells were cultivated up to 36 hours. Cells treated with only the PEI-TPP nanoparticles served as the controls.

The transfection efficacy of pEGFP-C1 was monitored in an inverted fluorescence microscope 36 hours after transfection, based on the number of cells with green fluorescence. Ten fields were randomly selected under 200× magnification, and the number of cells with green fluorescence were counted and averaged as the result.

\section{Cell-viability assay}

Cell viability was detected with the MTT assay. HeLa, HEK293T, HepG2, and MCF-7 cells and rOASFs were seeded into 96-well plates and cocultured with preset $\mathrm{N}: \mathrm{P}$ ratios of PEI-TPP and PEI for 36 hours. The medium was replaced with $10 \mu \mathrm{L}$ of $0.5 \mathrm{mg} / \mathrm{mL}$ MTT reagent and incubated for 4 hours at $37^{\circ} \mathrm{C}$. After removal of the culture medium, $100 \mu \mathrm{L}$ of dimethyl sulfoxide was added to each 
Table I Percentage cross-linking in PEI-TPP nanoparticles

\begin{tabular}{lll}
\hline Sample & $\begin{array}{l}\text { Attempted ionic } \\
\text { linking (\%) }\end{array}$ & $\begin{array}{l}\text { Realized ionic } \\
\text { linking (\%) }\end{array}$ \\
\hline 1 & 5 & $2.63 \pm 0.45$ \\
2 & 10 & $5.24 \pm 1.12$ \\
3 & 15 & $7.6 \pm 0.97$ \\
4 & 20 & $10.2 \pm 0.67$ \\
\hline
\end{tabular}

Abbreviations: PEI, polyethylenimine; TPP, tripolyphosphate.

well, and the absorbance was detected at $570 \mathrm{~nm}$ using an enzyme-linked immunosorbent assay plate reader (Varioskan ${ }^{\text {TM }}$ Flash MRX; Thermo Fisher Scientific). Cells not treated with PEI-TPP taken as $100 \%$ viability of the control cells, and wells only filled with MTT reagent served as blanks to standardize the absorbance. Cell viability (\%) was calculated as: absorbance transfected $/$ absorbance $_{\text {control }} \times 100 \% .^{24}$ All experiments were performed at least three times.

\section{Results}

\section{Preparation of PEI-TPP nanoparticles}

The amino positive charge of PEI was partially neutralized by anionic TPP through charge interactions, and then formed the PEI-TPP nanosize complex in aqueous solutions. The ionic linkage rate of PEI-TPP nanoparticles was measured using colorimetry of phosphate (Table 1).

\section{Characterization of nanoparticles}

The size and zeta potential of the nanoparticles were detected to characterize the PEI-TPP (10.2\%) nanoparticles. The particles were of uniform size and scattered light in the nanometer scale (about $120 \mathrm{~nm}$, Figure 1). With increasing amounts of TPP, the zeta potential and particle size of the PEI-TPP nanoparticles decreased in aqueous solution (Table 2). FTIR analysis showed PEI-TPP spectra peaks at $927 \mathrm{~cm}^{-1}$ (P-O-P stretching), $1,118 \mathrm{~cm}^{-1}$ (C-N stretching), $1,655 \mathrm{~cm}^{-1}$ (amino deformation), $3,413 \mathrm{~cm}^{-1}$ (amino stretching), and PEI spectra peaks at $2,836 \mathrm{~cm}^{-1}$ (amino stretching). The band at $897 \mathrm{~cm}^{-1}$ represented TPP in the nanoparticles

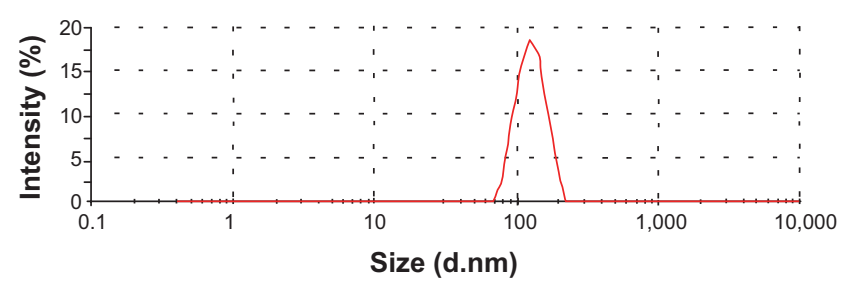

Figure I Size distribution of PEI-TPP (10.2\%) detected by a Zetasizer Nano ZS. Abbreviations: PEI, polyethylenimine; TPP, tripolyphosphate. Note: Zetasizer Nano ZS from Malvern Instruments, Malvern, UK.
Table 2 Particle-size and zeta-potential measurements of PEI-TPP nanoparticles (in $\mathrm{H}_{2} \mathrm{O}$ )

\begin{tabular}{llll}
\hline Sample & Samples & $\begin{array}{l}\text { Average particle } \\
\text { size }(\mathbf{n m})\end{array}$ & $\begin{array}{l}\text { Zeta potential } \\
(\mathbf{m V})\end{array}$ \\
\hline 1 & PEI-TPP $(2.63 \%)$ & $147.3 \pm 1.32$ & $20.3 \pm 4.26$ \\
2 & PEI-TPP (5.24\%) & $126 \pm 5.20$ & $10.7 \pm 0.47$ \\
3 & PEI-TPP (7.6\%) & $87.4 \pm 0.76$ & $9.5 \pm 2.13$ \\
4 & PEI-TPP (10.2\%) & $64.6 \pm 3.40$ & $7.2 \pm 0.53$ \\
5 & PEI & $301.4 \pm 2.46$ & $31.7 \pm 0.68$ \\
\hline
\end{tabular}

Abbreviations: PEI, polyethylenimine; TPP, tripolyphosphate.

(Figure 2, note arrows). This indicated that TPP combined with $\mathrm{PEI}$ through amino and $\mathrm{P}-\mathrm{O}$ bonds.

\section{Gel retardation}

The negative charge in the phosphate backbone of DNA was minimized through the combination of PEI-TPP or PEI to pDNA, which can retard DNA's electrophoresis rate. The electrophoresis results showed that with increasing amounts of PEI-TPP (N:P ratios 1:1, 5:1, 10:1, 15:1, 20:1, or 25:1) or PEI (N:P ratios 5:1, 10:1, or 15:1) complexed with DNA, the electrophoretic mobility of DNA was slowed. PEI at the $\mathrm{N}: \mathrm{P}$ ratio of 10:1 slowed the mobility of pDNA more than the other ratios, while PEI-TPP nanoparticles and DNA had a bigger weight:weight (wt:wt) ratio. Furthermore, PEI-TPP with $7.6 \%$ cross-linking exhibited the best retardation effect on DNA (Figure 3).

\section{DNase digestion assay}

An indicator of a good transfection vector is whether it can resist the degradation of nucleases in sera. In the DNase digestion experiment, heparin released whole pDNA nanoparticles exposed to DNase I effectively. The naked pDNA $(2 \mu \mathrm{g})$ was completely digested by DNase I within 15 minutes, but the PEI-TPP (7.6\%) nanocarrier efficiently protected pDNA from degradation (Figure 4).

\section{Transfection of siRNA by PEI-TPP nanoparticles}

Intracellular trafficking of the PEI-TPP (7.6\%)/FAMsiRNA complex in HEK293T cells was observed by confocal microscopy from 15 minutes to 4 hours (Figure 5, A-G). After 30 minutes, discrete fluorescent dots appeared in the cytoplasm and then accumulated around the nucleus over time (Figure 5, B-F). The results showed that PEI-TPP/siRNA complexes were efficiently transported into the cells.

We also tested the efficiency with which PEI-TPP (7.6\%) nanoparticles delivered siRNA into HepG2, HEK293T, and 
A

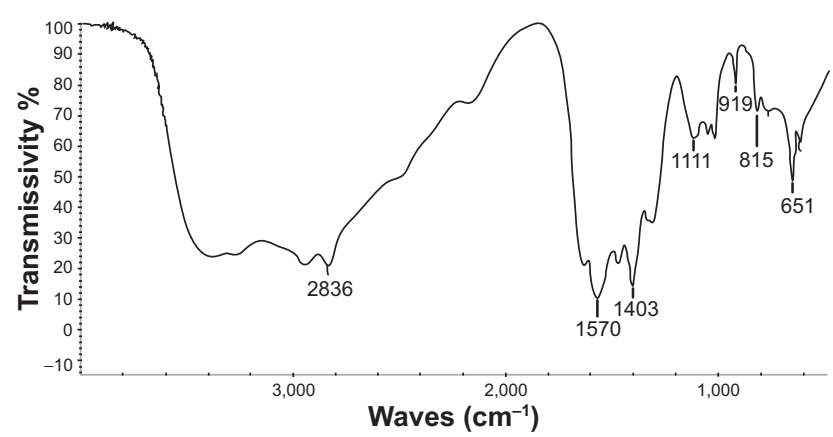

B

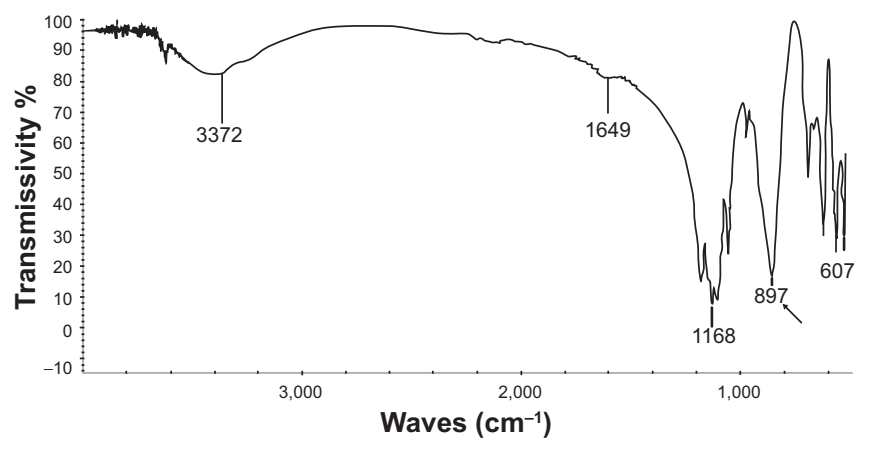

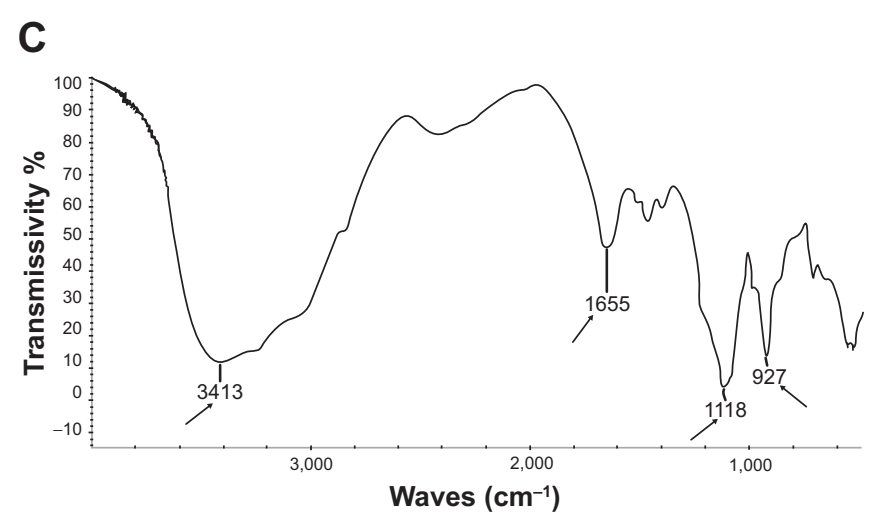

Figure 2 Fourier-transform infrared spectra of (A) PEI, (B) TPP, and (C) PEI-TPP (I0.2\%).

Note: Arrows indicate spectra peaks.

Abbreviations: PEI, polyethylenimine; TPP, tripolyphosphate.

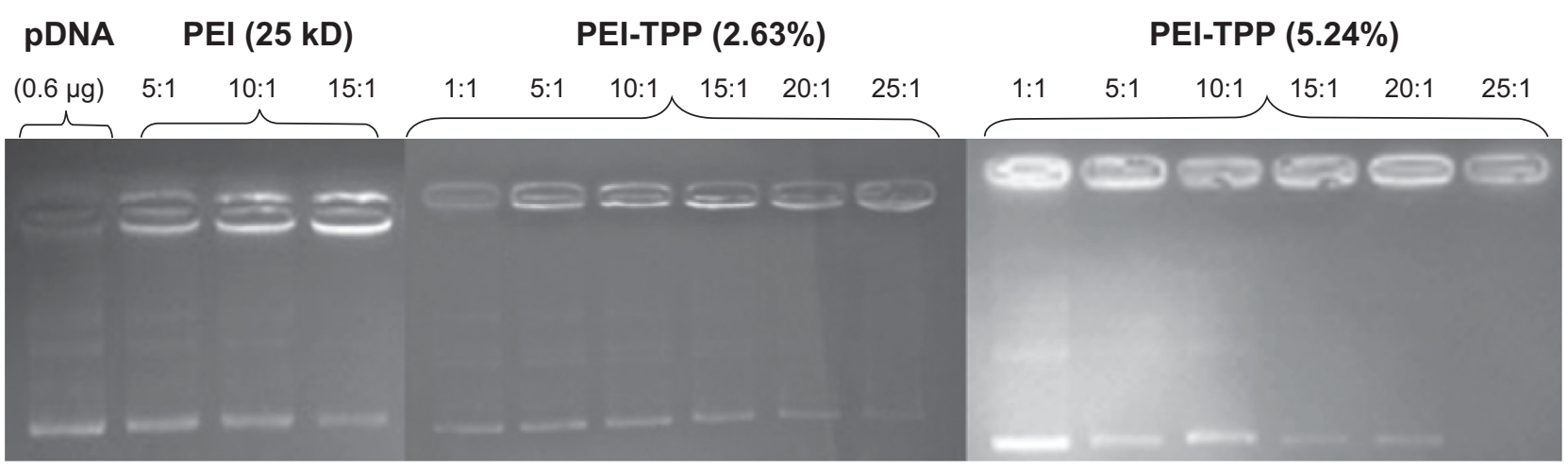

PEI-TPP (7.6\%)

\section{PEI-TPP (10.2\%)}

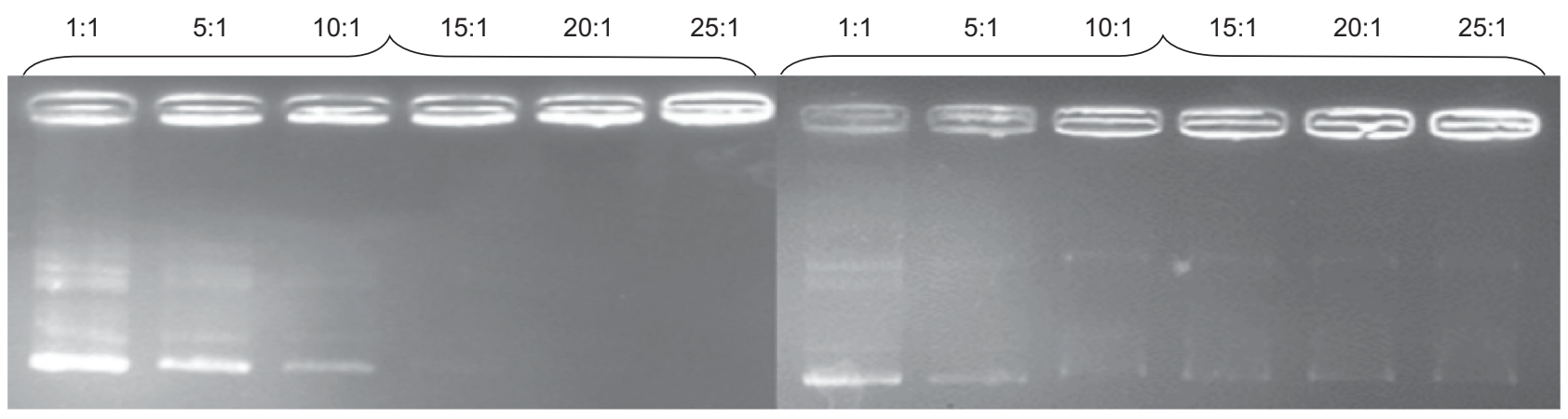

Figure 3 Mobility assay of PEI-TPP/DNA and PEI/DNA complexes at various N:P ratios and cross-linking rates.

Abbreviations: PEl, polyethylenimine; TPP, tripolyphosphate; DNA, deoxyribonucleic acid; pDNA, plasmid deoxyribonucleic acid; N:P ratios, nitrogen in PEl to phosphorus in DNA. 


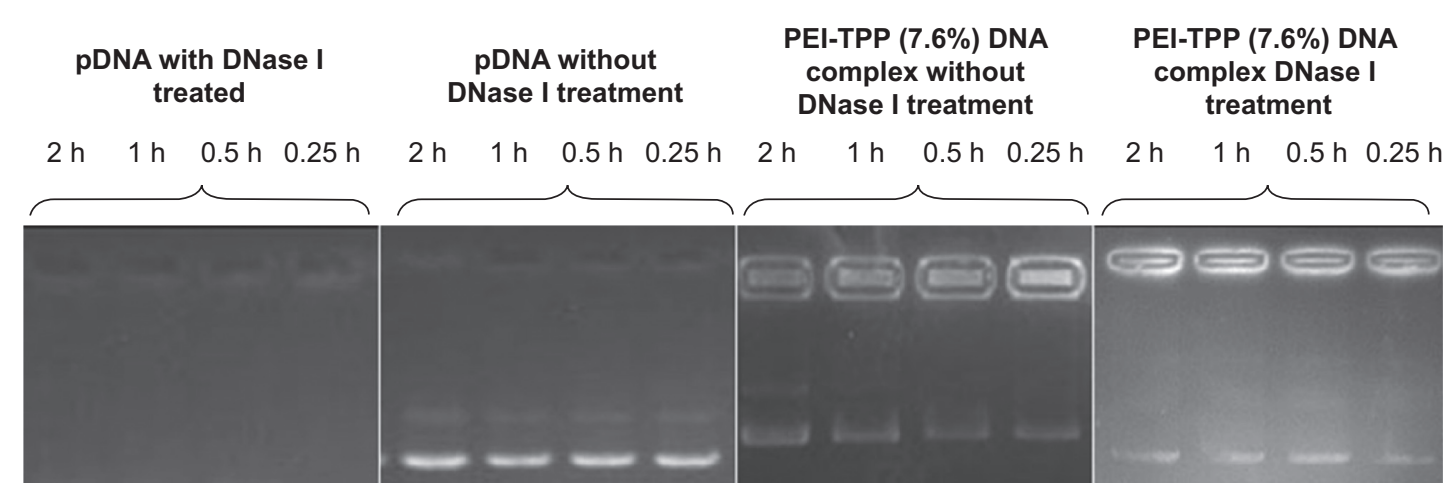

Figure 4 DNase I digestion assay. The PEI-TPP (7.6\%)/DNA complex was treated with DNase I at an N:P ratio of I0:I for different time intervals.

Abbreviations: PEI, polyethylenimine; TPP, tripolyphosphate; DNA, deoxyribonucleic acid; pDNA, plasmid deoxyribonucleic acid; DNase I, deoxyribonuclease I; N:P ratios, nitrogen in PEl to phosphorus in DNA; h, hour.

rOASF cells. PEI-TPP at N:P 10:1 was the most efficient (Figure 6), being 1.78-, 2.5-, and 1.8-fold higher than PEI (N:P 10:1) alone in rOASF, HEK293T, and HepG2 cells, respectively. These results show that the PEI-TPP vector can powerfully convey siRNA into different types of cells.

\section{Transfection of plasmid by PEI-TPP nanoparticles}

The transfection efficacy of the PEI-TPP nanocarrier to deliver pDNA was evaluated in HeLa, HEK293T, HepG2, and MCF-7 cell lines and primary rOASFs. Cells were processed for 4 hours with PEI-TPP nanoparticles complexed with $1 \mu \mathrm{g}$ pEGFP-C1 and increasing amounts of PEI-TPP (N:P 1:1, 5:1, 10:1, 15:1, 20:1, or 25:1) or PEI (PEI:DNA 10:1, Figure 7). After 36 hours, the cells were examined for GFP under a fluorescence microscope. In general, at the N:P ratio of 10:1, PEI-TPP (10.2\%) nanoparticles resulted in the highest levels of GFP (Figure 7, B-D). In HeLa and HEK293T cells with more TPP content, the delivery efficacy of PEI-TPP (10.2\%) reached the maximum at $\mathrm{N}: \mathrm{P}=10: 1$, but gradually reduced as TPP in the particles increased (Figure 7, A and B).

The transfection efficacy of pEGFP-C1 by PEI-TPP at 10.2\% (N:P 10:1) was 1.49-, 4.28-, 2.84-, and 1.38-fold greater than that of PEI (N:P 10:1) in HeLa, 293T, HepG2, and MCF-7 cells, respectively (Figure 7, A-D). In rOASFs, PEI-TPP (7.6\%) N:P 25:1 showed greater transfection efficacy than PEI (2.07-fold, Figure 7E). Similar to HepG2 cells, in rOASFs the transfection efficiency of PEI-TPP $(10.2 \%)$ at N:P 20:1 was 3.6-fold higher than the PEI (Figure 7C).

\section{PEI-TPP nanoparticles have much less effect on cell viability}

To estimate the effect of PEI-TPP/DNA complexes on cell viability, an MTT assay was performed. Cell viability was $>90 \%$ at different $\mathrm{N}: \mathrm{P}$ ratios of $\mathrm{PEI}-\mathrm{TPP} / \mathrm{pDNA}$ in HEK293T, HepG2, and HeLa cells, and was 70\% in the $\mathrm{MCF}-7$ cells. In contrast, the proliferation rate was $<56 \%$ in cells treated with PEI/DNA complexes (Figure 8). These data suggest that PEI-TPP nanoparticles have much less cytotoxicity than PEI.

\section{Discussion}

Gene therapy has presented enormous opportunities for the treatment of congenital and acquired diseases. ${ }^{25-28}$ However, the main obstacle to application has been the lack of a safe and effective carrier system. Nonviral vectors are lower in risk, and can be modified to meet the needs of individualized treatment. These include cationic polymers, which concentrate DNA or RNA into a stable nanoparticle and avoid the problems associated with viral carriers. ${ }^{11,28,29}$ Among cationic polymers, such as chitosan, polyamidoamine dendrimers, poly-L-lysine, and poly(2-[dimethylamino] ethyl methacrylate), ${ }^{30,31}$ branched PEIs can efficiently link with DNA at different physiological $\mathrm{pH}$ values and form PEI-DNA complexes that are diminutive enough to be endocytosed. ${ }^{32}$ Although these characteristics of PEI make it an attractive candidate for gene transport, it can cause chargeassociated cytotoxicity at higher concentrations. ${ }^{15,33}$ In our study, we reduced the charge-related cytotoxicity of branched PEI via ionic interactions with the anionic molecule TPP. We achieved well-defined carrier nanoparticles of PEI by cross-linking TPP.

PEI-TPP nanoparticles were synthesized in sizes ranging from $65 \mathrm{~nm}$ to $147 \mathrm{~nm}$. These possessed a positive zeta potential that negatively correlated with the content of TPP in the particles. The reduced size of the nanoparticles might be due to the electrostatic interaction between the amines of PEI and the incremental amount of anionic TPP. Monitoring 


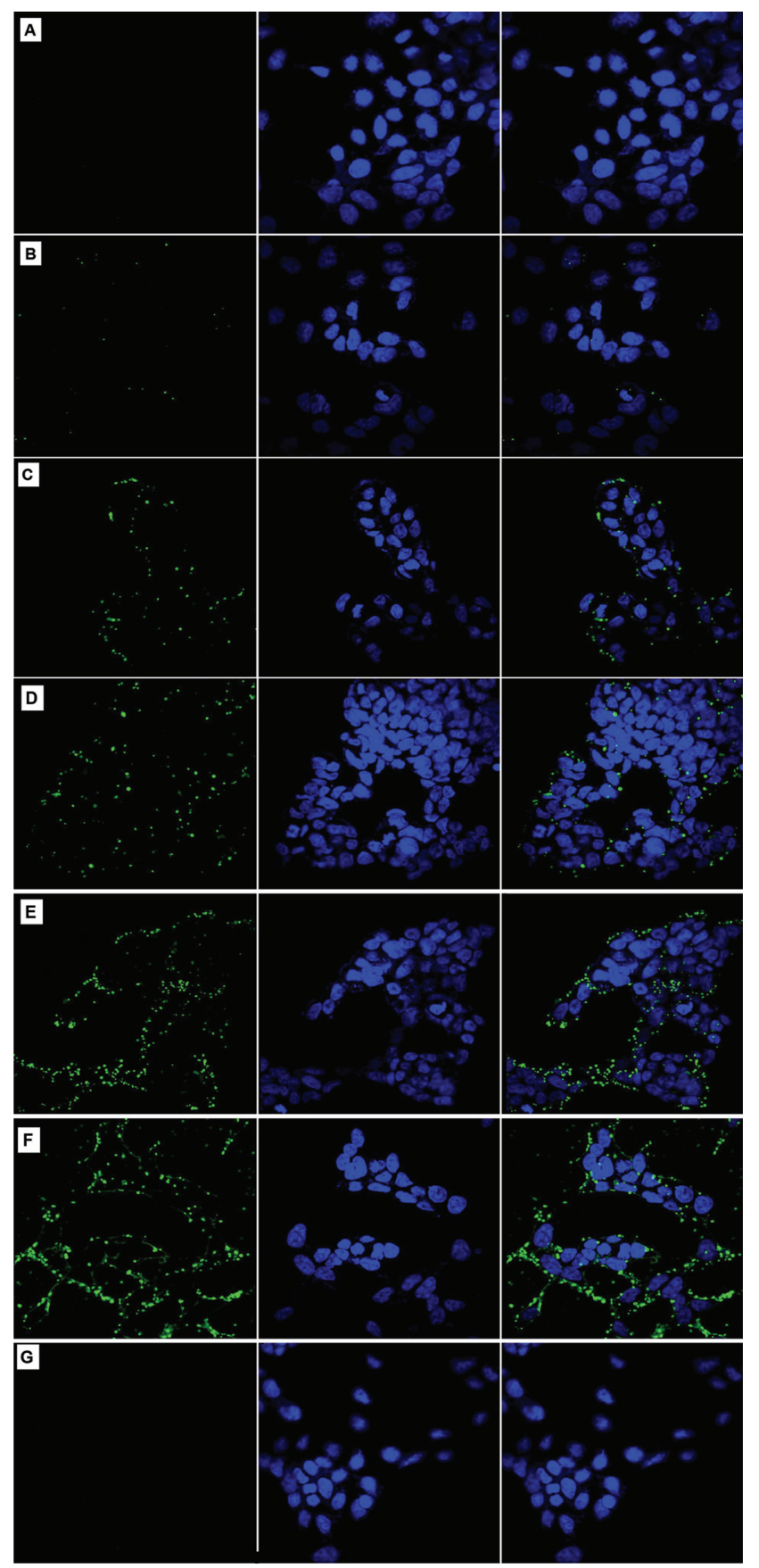

Figure 5A-G The cellular uptake of PEI-TPP (7.6\%, N:P ratio 10:I)/siRNA in HEK293T was visualized by overlaying images obtained by EGFP and DAPI filters: left image from FAM channel; center image from DAPI channel; right image from combined FAM channel and DAPI channel. Images of human embryonic kidney 293T cells transfected with PEI-TPP (7.6\%)/siRNA at different time points: (A) I 5 minutes, (B) 30 minutes, (C) I hour, (D) 2 hours, (E) 3 hours, (F) 4 hours, (G) control.

Abbreviations: PEl, polyethylenimine; TPP, tripolyphosphate; siRNA, small interfering ribonucleic acid; EGFP, enhanced green fluorescent protein; DAPI, 4',6diamidino-2-phenylindole; FAM, fluorouracil, adriamycin (doxorubicin), mitomycin; $\mathrm{N}: \mathrm{P}$ ratios, nitrogen in PEl to phosphorus in deoxyribonucleic acid.

the electrophoretic mobility of the PEI-TPP and DNA mixture through agarose gels revealed the ability of the PEI-TPP vector to bind DNA. Compared to PEI, PEI-TPP nanoparticles were more effective in hindering the mobility

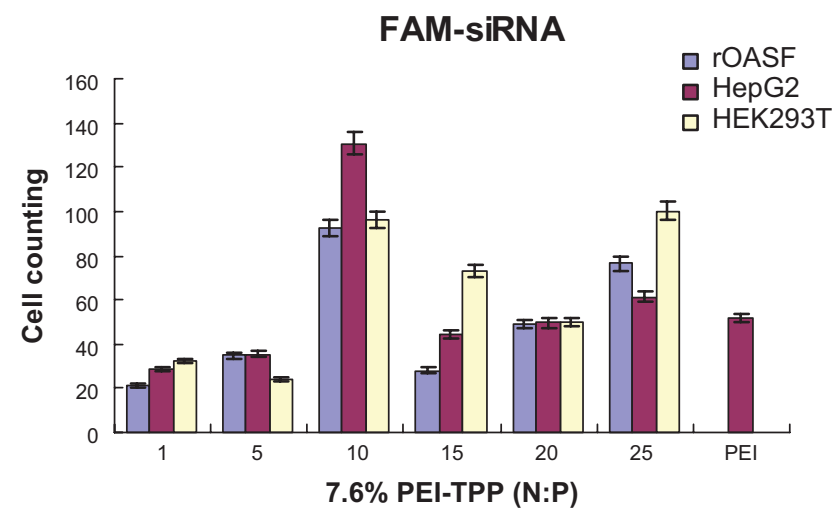

Figure 6 Different N:P ratios of PEI-TPP (7.6\%) as an effective carrier in delivering siRNA in rabbit osteoarthritis synovial fibroblast (rOASF), HepG2, and human embryonic kidney (HEK)-293T cells.

Abbreviations: FAM, fluorouracil, adriamycin (doxorubicin), mitomycin; PEI, polyethylenimine; TPP, tripolyphosphate; N:P ratios, nitrogen in PEI to phosphorus in deoxyribonucleic acid; siRNA, small interfering ribonucleic acid.

of pDNA at lower N:P ratios, probably because in PEI-TPP the positive charge of PEI was neutralized by anionic TPP. Consequently, the PEI-TPP nanoparticles were more effective in retarding the mobility of pDNA than PEI.

A perfect gene-delivery vector should prevent cutting of the target gene by nuclease. To evaluate the ability of PEI-TPP nanoparticles to protect the transported gene, we performed a DNA digestion experiment and found that PEITPP $(7.6 \%)$ nanoparticles efficiently protected $\mathrm{pDNA}$ against DNase I for more than 2 hours. Furthermore, we assessed the intracellular trafficking of the PEI-TPP $(7.6 \%) /$ siRNA complex, and found that it was internalized by HEK293T cells within 30 minutes, and was gathered around the nucleus even after 4 hours. These results showed that the existence of TPP did not inhibit the cellular endocytosis of nanoparticles and the associated RNA complex.

Next, we compared the effectiveness of PEI-TPP and PEI (branched $25 \mathrm{kDa}$ ) particles to deliver a GFP-expression plasmid into HEK293T, HeLa, HepG2, and MCF-7 cells, as well as primary rOASFs. Although PEI-TPP (10.2\%) nanoparticles did not achieve the best transfection efficacy, they presented much better than PEI in the four cell lines and rOASFs. For PEI, we chose the N:P ratio of 10:1, but it has been reported that the best transfection rate of PEI is at $\mathrm{N}: \mathrm{P}$ ratios of 9-13.5:1. ${ }^{10}$ These data provide evidence that the transfection efficacy of PEI-TPP nanoparticles surpasses that of PEI.

It has been reported that the transfection efficiency of polyplexes is cell-specific. ${ }^{34}$ To determine the specificity of the newly prepared PEI-TPP/pDNA complexes in the present study, we chose HEK293T, HeLa, HepG2, 
A

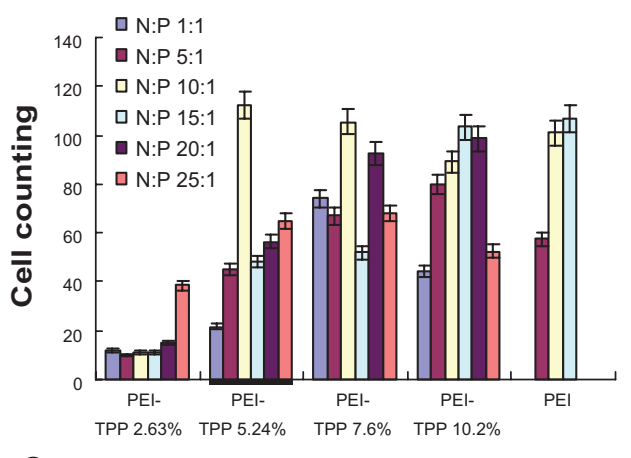

C

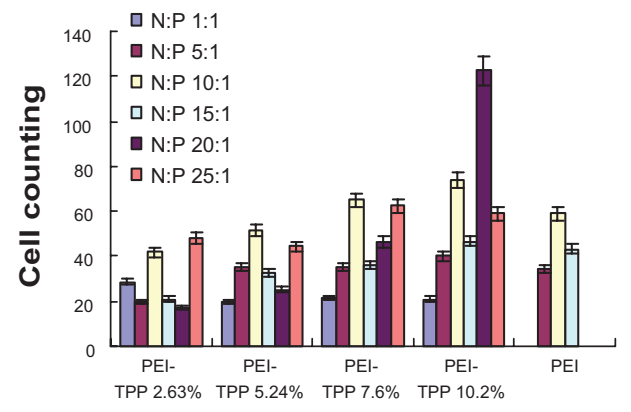

B

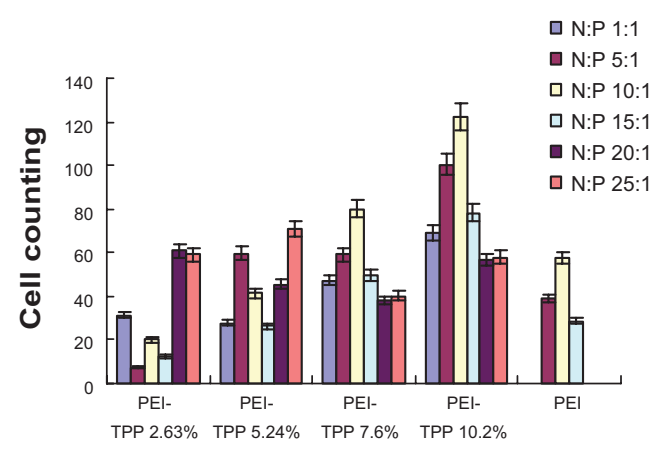

D

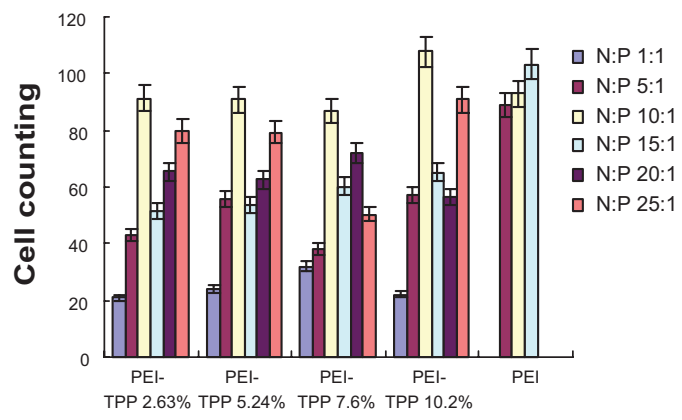

E

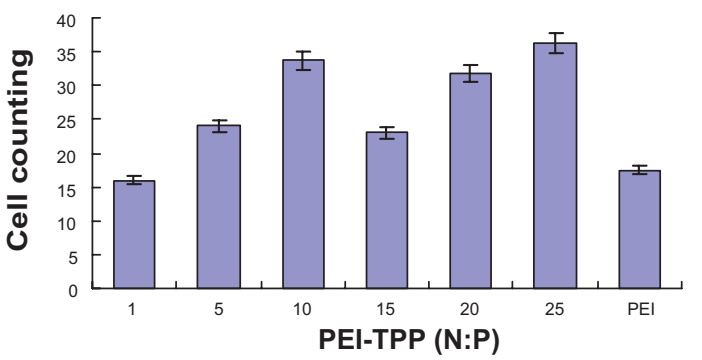

Figure 7A-E Green fluorescent protein expression in HeLa, human embryonic kidney (HEK)-293T, HepG2, Michigan Cancer Foundation (MCF)-7, and rabbit osteoarthritis synovial fibroblast (rOASF) cells transfected with PEI-TPP/pDNA and PEI/pDNA complexes. Transfection profiles obtained at various N:P ratios for (A) HeLa, (B) HEK293T, (C) HepG2, (D) MCF-7 cells, and (E) primary rOASFs.

Abbreviations: PEl, polyethylenimine; TPP, tripolyphosphate; DNA, deoxyribonucleic acid; pDNA, plasmid deoxyribonucleic acid; N:P ratios, nitrogen in PEI to phosphorus in DNA.

and MCF-7 cells and primary rOASFs and tested PEI-TPP (10\%)/DNA. PEI was more efficient in HeLa and HepG2 cells than in the other two cell lines, perhaps due to cell specificity. Transfection with the PEI-TPP (7.6\%)/ pDNA mixture was cell-specific and in the order of HEK293T > HepG2 > HeLa > MCF-7, and the transfection of PEI-TPP nanoparticles in different cells showed almost the same trend. Furthermore, the efficacy of the PEI-TPP vector to transfect siRNA but not pDNA was also investigated. Compared to the efficiency of transfection by PEI in rOASFs and HepG2 and 293T cells, that of FAMspecific HPV16 E6 siRNA was 1.78-, 2.5-, and 1.85-fold higher, respectively.

Charge-related cytotoxicity is one of the main obstacles in the use of PEI as a gene vector. ${ }^{35}$ In this study, we showed that neutralizing the charge on PEI with TPP resulted in significantly decreased cytotoxicity in HeLa, HEK293T, HepG2, and MCF-7 cells. Further, nanoparticles containing less TPP did more harm to cells than those with more. PEI possesses more ionic density, which is associated with cytotoxicity. ${ }^{36-38}$ The weakened toxicity of the PEI-TPP nanovector is likely due to the electrostatic interaction between amine anions from TPP, which decreased the overall positive charge of the complex.

\section{Conclusion}

In this study, we modified the multipurpose cationic polymer gene-delivery system PEI through charge interactions between PEI and TPP. These PEI-TPP nanoparticles have significantly higher transfection efficiency than PEI for 
A

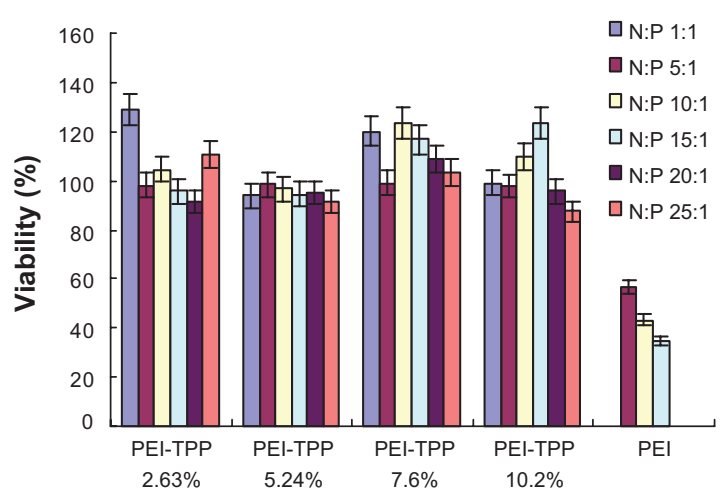

C

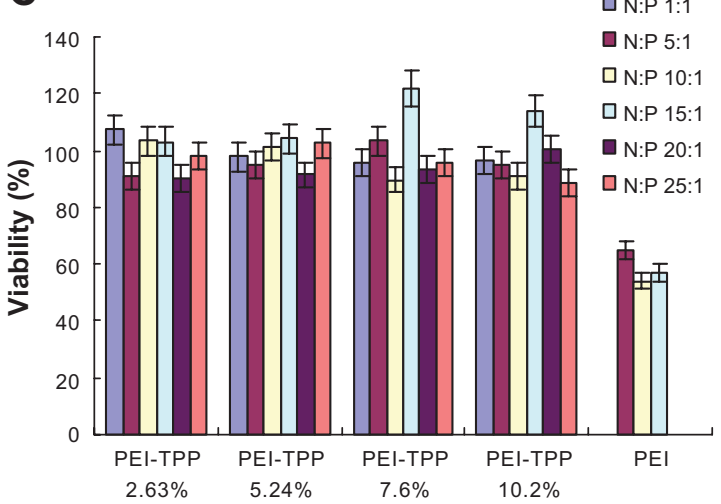

B
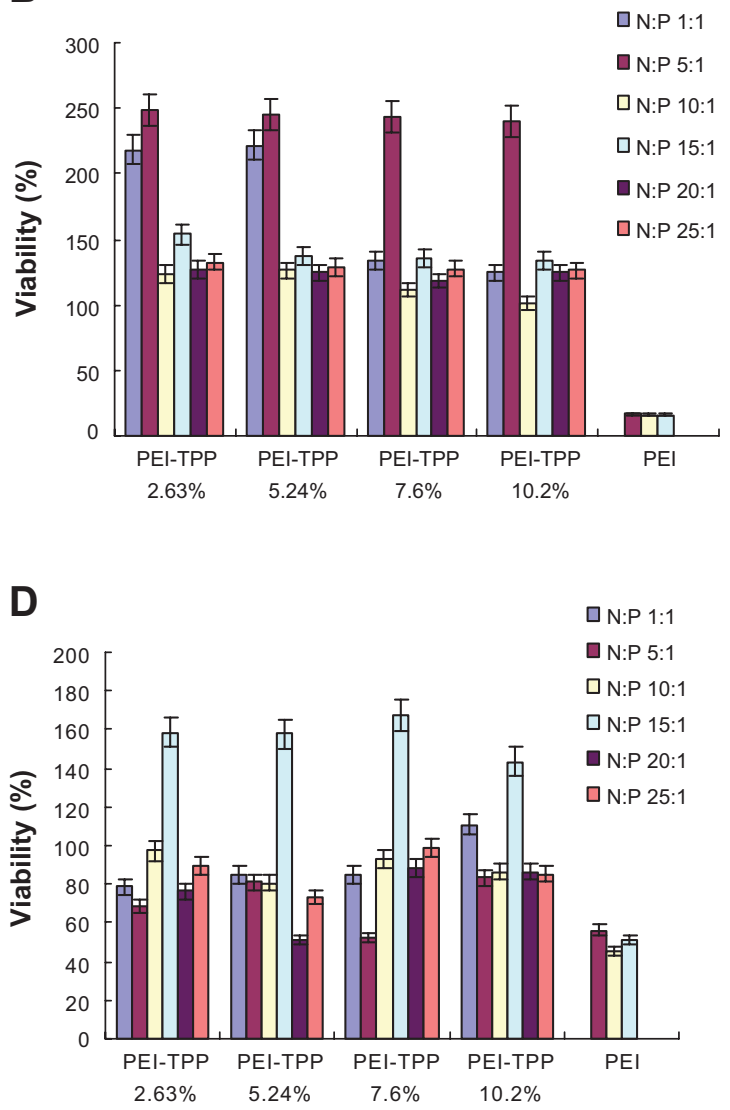

Figure 8 Cell-viability profile of PEI-TPP/DNA complexes at different N:P ratios in (A) human embryonic kidney (HEK)-293T, (B) HeLa, (C) HepG2, and (D) Michigan Cancer Foundation 7 cells. The cytotoxicity of PEI-TPP/DNA was much lower than that of PEI/DNA complexes in HeLa, HEK293T, and HepG2 cells.

Abbreviations: PEI, polyethylenimine; TPP, tripolyphosphate; DNA, deoxyribonucleic acid; N:P ratios, nitrogen in PEI to phosphorus in DNA.

both pDNA and siRNA, and significantly lower cytotoxicity in cell lines and primary cells, because of the masking of the high cationic charge of PEI by TPP. The PEI-TPP nanoparticles thus have potential application in gene delivery.

\section{Acknowledgments}

This work was supported by the National Key Technologies R \& D Program of China (2012BAI37B01) and the National Special R \& D Program of Major New Drugs (2012ZX09303009-003).

\section{Disclosure}

The authors report no conflicts of interest in this work.

\section{References}

1. Katas H, Alpar HO. Development and characterisation of chitosan nanoparticles for siRNA delivery. $J$ Control Release. 2006;115(2): 216-225.

2. Fernandes JC, Qiu X, Winnik FM, et al. Linear polyethylenimine produced by partial acid hydrolysis of poly(2-ethyl-2-oxazoline) for DNA and siRNA delivery in vitro. Int J Nanomedicine. 2013;8:409-4102.
3. Eroglu E, Tiwari PM, Waffo AB, et al. A nonviral pHEMA+ chitosan nanosphere mediated high efficiency gene delivery system. Int $J$ Nanomedicine. 2013;8:1403-1415.

4. Liang X, Ren X, Liu Z, et al. An efficient nonviral gene-delivery vector based on hyperbranched cationic glycogen derivatives. Int $J$ Nanomedicine. 2014;9:419-435.

5. Yang Y, Nunes FA, Berencsi K, Furth EE, Gönczöl E, Wilson JM. Cellular immunity to viral antigens limits E1-deleted adenoviruses for gene therapy. Proc Natl Acad Sci U S A. 1994;91(10): 4407-4411.

6. Miller N, Vile R. Targeted vectors for gene therapy. FASEB J. 1995;9(2): 190-199.

7. Dai YK, Zhou R, Liu L, Lu Y, Qi JP, Wu W. Liposomes containing bile salts as novel ocular delivery systems for tacrolimus (FK506): in vitro characterization and improved corneal permeation. Int J Nanomedicine. 2013;8:1921-1933.

8. Hwang SJ, Davis ME. Cationic polymers for gene delivery: designs for overcoming barriers to systemic administration. Curr Opin Mol Ther. 2001;3(2):183-191.

9. Zorko M, Langel U. Cell-penetrating peptides: mechanism and kinetics of cargo delivery. Adv Drug Delivery Rev. 2005;57(4):529-545.

10. Boussif O, Lezoualc'h F, Zanta MA, et al. A versatile vector for gene and oligonucleotide transfer into cells in culture and in vivo: polyethylenimine. Proc Natl Acad Sci U S A. 1995;92(16):7297-7301.

11. Lungwitz U, Breunig M, Blunk T, Göpferich A. Polyethyleniminebased non-viral gene delivery systems. Eur J Pharm Biopharm. 2005;60(2):247-266. 
12. Jeudy G, Salvadori F, Chauffert B, Solary E, Vabres P, Chluba J. Polyethylenimine-mediated in vivo gene transfer of a transmembrane superantigen fusion construct inhibits B16 murine melanoma growth. Cancer Gene Ther. 2008;15(11):742-749.

13. Nimesh S, Goyal A, Pawar V, et al. Polyethylenimine nanoparticles as efficient transfecting agents for mammalian cells. J Control Release. 2006;110(2):457-468.

14. Patnaik S, Aggarwal A, Nimesh S, et al. PEI-alginate nanocomposites as efficient in vitro gene transfection agents. $J$ Control Release. 2006;114(3):398-409.

15. Swami A, Aggarwal A, Pathak A, et al. Imidazolyl-PEI modified nanoparticles for enhanced gene delivery. Int J Pharm. 2007;335(1-2): 180-192.

16. Nimesh S, Aggarwal A, Kumar P, Singh Y, Gupta KC, Chandra R. Influence of acyl chain length on transfection mediated by acylated PEI nanoparticles. Int J Pharm. 2007;337(1-2):265-274.

17. Chen J, Gao X, Hu K, et al. Galactose-poly(ethylene glycol)polyethylenimine for improved lung gene transfer. Biochem Biophys Res Commun. 2008;375(3):378-383.

18. Tripathy S, Das S, Chakraborty SP, Sahu SK, Pramanik P, Roy S. Synthesis, characterization of chitosan-tripolyphosphate conjugated chloroquine nanoparticle and its in vivo anti-malarial efficacy against rodent parasite: a dose and duration dependent approach. Int J Pharm. 2012;434(1-2):292-305.

19. Gaspar VM, Sousa F, Queiroz JA, Correia IJ. Formulation of chitosanTPP-pDNA nanocapsules for gene therapy applications. Nanotechnology. 2011;22(1):015101.

20. Du WL, Xu YL, Xu ZR, Fan CL. Preparation, characterization and antibacterial properties against $E$. coli $\mathrm{K} 88$ of chitosan nanoparticles loaded with copper ions. Nanotechnology. 2008;19(8):085707.

21. Patnaik S, Arif M, Pathak A, Kurupati R, Singh Y, Gupta KC. Crosslinked polyethylemine-hexametaphosphate nanoparticles to deliver nucleic acids therapeutics. Nanomedicine. 2010;6(2):344-354.

22. Schowalter DB, Kay MA. Gene therapy: a status report. Pediatr Ann. 1997;26(9):562-568.

23. Liu SQ, Qiu B, Chen LY, Peng H, Du YM. The effects of carboxymethylated chitosan on metalloproteinase-1,-3 and tissue inhibitor of metalloproteinase-1 gene expression in cartilage of experimental osteoarthritis. Rheumatol Int. 2005;26(1):52-57.

24. Gil ES, Wu L, Xu L, Lowe TL. $\beta$-Cyclodextrin-poly( $\beta$-amino ester) nanoparticles for sustained drug delivery across the blood-brain barrier. Biomacromolecules. 2012;13(11):3533-3541.
25. Gu WY, Wu CT, Chen JZ, Xiao Y. Nanotechnology in the targeted drug delivery for bone diseases and bone regeneration. Int J Nanomedicine. 2013;8:2305-2317.

26. Russell SJ. Science, medicine, and the future. Gene therapy. BMJ. 1997;315(7118):1289-1292.

27. Anchordoquy TJ, Allison SD, Molina MC, Girouard LG, Carson TK. Physical stabilization of DNA-based therapeutics. Drug Discov Today. 2001;6(9):463-470.

28. Patil SD, Rhodes DG, Burgess DJ. DNA-based therapeutics and DNA delivery systems: a comprehensive review. AAPS J. 2005;7(1): E61-E77.

29. Bello Roufaï M, Midoux P. Histidylated polylysine as DNA vector: elevation of the imidazole protonation and reduced cellular uptake without change in the polyfection efficiency of serum stabilized negative polyplexes. Bioconjug Chem. 2001;12(1):92-99.

30. Midoux P, Monsigny M. Efficient gene transfer by histidylated polylysine/pDNA complexes. Bioconjug Chem. 1999;10(3):406-411.

31. Walker GF, Fella C, Pelisek J, et al. Toward synthetic viruses: endosomal $\mathrm{pH}$-triggered deshielding of targeted polyplexes greatly enhances gene transfer in vitro and in vivo. Mol Ther. 2005;11(3): $418-425$.

32. Godbey WT, Wu KK, Mikos AG. Tracking the intracellular path of poly(ethylenimine)/DNA complexes for gene delivery. Proc Natl Acad Sci US A. 1999;96(9):5177-5181.

33. Fischer D, Bieber T, Li Y, Elsässer HP, Kissel T. A novel non-viral vector for DNA delivery based on low molecular weight, branched polyethylenimine: effect of molecular weight on transfection efficiency and cytotoxicity. Pharm Res. 1999;16(8):1273-1279.

34. Midoux P, Pichon C, Yaouanc JJ, Jaffrès PA. Chemical vectors for gene delivery: a current review on polymers, peptides and lipids containing histidine or imidazole as nucleic acids carriers. Br J Pharmacol. 2009;157(2):166-178.

35. Lu H, Dai Y, Lv L, Zhao H. Chitosan-graft-polyethylenimine/DNA nanoparticles as novel non-viral gene delivery vectors targeting osteoarthritis. PLoS One. 2014;9(1):e84703.

36. Putnam D, Gentry CA, Pack DW, Langer R. Polymer-based gene delivery with low cytotoxicity by a unique balance of side-chain termini. Proc Natl Acad Sci U S A. 2001;98(3):1200-1205.

37. Jiang HL, Kim YK, Arote R, et al. Chitosan-graft-polyethylenimine as a gene carrier. J Control Release. 2007;117(2):273-280.

38. Stern ST, Johnson DN. Role for nanomaterial-autophagy interaction in neurodegenerative disease. Autophagy. 2008;4(8):1097-1100.
International Journal of Nanomedicine

\section{Publish your work in this journal}

The International Journal of Nanomedicine is an international, peerreviewed journal focusing on the application of nanotechnology in diagnostics, therapeutics, and drug delivery systems throughout the biomedical field. This journal is indexed on PubMed Central, MedLine, CAS, SciSearch ${ }^{\circledR}$, Current Contents ${ }^{\circledR} /$ Clinical Medicine,

\section{Dovepress}

Journal Citation Reports/Science Edition, EMBase, Scopus and the Elsevier Bibliographic databases. The manuscript management system is completely online and includes a very quick and fair peer-review system, which is all easy to use. Visit http://www.dovepress.com/ testimonials.php to read real quotes from published authors. 